\section{Overregulated biotechnology}

SIR - Nowhere is the gulf between politicians' rhetoric and their actions more pronounced than in US science and technology policy. One need only contrast the negative impact of the administration's biotechnology policies with the lofty goals outlined in the document Science and the National Interest (see Nature 370, 317; 1994).

Thus the policy document offers as a goal "a stable science-based regulatory system". The reality is that at the same time as funding is down, biotechnology regulation has become increasingly intrusive, unscientific and focused on negligible-risk activities.

The Department of Agriculture (USDA) has required unnecessary permits for more than 1,400 field trials of genetically modified plants, all of them of negligible risk. The Food and Drug Administration (FDA), which has a generally positive 15 -year track record in regulating biotechnology, recently announced that it will soon require food manufacturers to notify the FDA before marketing foods manufactured with high-precision recombinant DNA techniques - while exempting those developed with other techniques, regardless of possible risk.

Biotechnology regulatory policies of the Environmental Protection Agency (EPA) are the most egregious of all. In early September, the EPA published regulations for biotechnology control agents. EPA targets only products made with the most precise and predictable new genetic methodologies. The agency also plans to expand its regulatory dominion to a whole new category of products plants that are made resistant to pests by using the new genetic techniques. These garden and farm plants will be regulated even more stringently than chemicals similar to DDT or parathion. Yet plant breeders have been creating and farmers using genetically improved plant varieties safely for more than a century without government regulation.

These regulations make neither scientific nor economic sense. The USDA, FDA and EPA regulatory approaches fly in the face of a broad scientific consensus that the new biotechnology is an extension, or refinement, of earlier techniques of genetic manipulation. Moreover, their regulatory policies constitute, in effect, a tax on innovation that uses the new biotechnology. Ineluctably, these antiinnovative policies will discourage research using the newer, more precise techniques, denying consumers an array of new products. There is a peculiar irony in the administration's inconsistency: its policies have preferentially undermined research on precisely the kinds of lowvalue-added but socially important pro- ducts that should appeal to the administration's policymakers - safer and more nutritious foods, improved bioremediation agents, alternatives to chemical pesticides and fertilizers and other environmentally friendly innovations.

\section{Henry I. Miller}

Hoover Institution \&

Institute for International Studies,

Stanford University,

Stanford, California 94305-6010, USA

\section{US health reform}

SIR - You say that the health plan proposed by a "well-meaning" Clinton administration violates "the Hippocratic oath to do no harm" (Nature 371, 2; 1994). If you were ever to read the oath, you would quickly discover that it enjoins the physician to act for the benefit of his patients rather than for "their hurt or for any wrong". In other words, what the oath prohibits is the intentional infliction of damage on patients, not unintended bad outcomes. If Hippocrates had prohibited bad outcomes resulting from treatment by "well-meaning" physicians, no one in ancient Greece would have been qualified to practise medicine.

Politicians in the United States who qualify their positions on health-care reform with similarly twisted renditions of Hippocrates neglect to consider other public-policy consequences of the oath. If Hippocrates were in charge today, there would be no medical schools, because modern doctors are disinclined to work for nothing ("I will teach ... this art without fee or covenant"), and there would be no health insurance, public or private, because doctors would be prohibited from communicating to third-party payers any information about the identity, condition, or treatment of patients ("Whatever things I see or hear . . . in my attendance on the sick ... I will keep silence thereon, counting such things to be as sacred secrets").

Elsewhere in the same issue, you publish a communication in which chain letters are classified as "mind viruses". Politically motivated misquotations may not qualify as mind viruses, but they are at least mind bacteria.

\section{Gareth Penn}

13-1/2 Linda Avenue,

San Rafael, California 94903, USA

\section{Origin of life}

SIR - In his recent article ${ }^{1}$ on the origin of the cell membrane, John Maddox focuses on the model of Ourisson and Nakatani. The features of this model have striking similarities to another theory, not men- tioned by Maddox, namely that of Günter Wächtershäuser ${ }^{2}$. This latter theory entails the origin of the cell membrane and is based upon an autocatalytic surface metabolism. Wächtershäuser's theory is steadily gaining prominence and has been commented upon by Karl Popper ${ }^{3,4}$ and Russell, Hall and Gaze ${ }^{5}$.

A key role in the lipid synthesis section of Wächtershäuser's theory is also played by terpenoids (phosphorylated isoprenoids) bound to a solid surface (pyrite) which spring from an ancient pathway to form lipid constituents which undergo condensations and contribute to growth of the lipid sheet. In a mechanism similar to that of Ourisson and Nakatani described by Maddox, at some point the lipid sheet detaches from the surface to form an enclosure. In both models, synthetic pathways for structural and functional components are included in these cell precursors.

Although the two theories have much common ground with respect to the origin of membranes, not only is Wächtershäuser's theory not referred to by Maddox, but Wächtershäuser does not mention the work of Ourisson (or Nakatani) in either of his major articles ${ }^{2}$.

Russell Hill

Peter Århem

Nobel Institute,

Karolinska Institute,

S-171 77 Stockholm, Sweden

B. I. B. LIndahl

Department of Philosophy,

University of Stockholm,

S-106 91 Stockholm, Sweden

1. Maddox, J. Nature 371, 101 (1994).

2. Wächtershäuser, G. Microb. Rev. 52, $482-484$ (1988);

Prog. Biophys. molec. Biol. 58, 85-201 (1992).

3. Popper, K. R. Nature 344, 387 (1990).

4. Popper, K. R. et al. theor. Med. 14, 167-180 (1993).

5. Russelt, M. J. et al. Nature 344, 387 (1988).

\section{Pi remembered}

SIR - As a postscript to the silly season, and while $\pi$ is still in the news (Nature 370, $323 ; 1994)$, your readers may appreciate a mnemonic for 30 digits of $\pi$. The number of letters in each word represents the value of the digit:-

Que j'aime à faire apprendre un nombre util aux sages!

Immortel Archimêde, artiste ingénieur,

Qui de ton jugement peut priser la valeur?

Pour moi, ton problème eut de pareils avantages

My source (G. F. Hull, An Elementary Survey of Modern Physics, Macmillan, New York; 1938) gives no indication of who wrote this interesting, if not useful, poem, how he derived the value of $\pi$, or whether the Editor of Nature would have approved of his method of derivation.

\section{W. E. Ormerod}

The Old Rectory,

Padworth,

Reading, RG7 4JD, UK

NATURE · VOL 371 • 20 OCTOBER 1994 